\title{
Drawing Attention: Ways of Knowing Derived in the Movement of the Pencil
}

\section{Tamarin Norwood}

\begin{abstract}
This chapter explores interpretations and distortions of the visual world that occur through drawing and mind wandering. Tamarin Norwood's writing is informed by scientific literature on doodling, fidgeting, concentration and mind wandering considered in the course of her Hubbub research, and draws on chance encounters shared with collaborators in The Hub. These interactions have helped shape the imaginative approach Tamarin takes to her writing, foregrounding the possibility of movement as an impetus for generating new thought.
\end{abstract}

Keywords Blindness · Drawing · Haptic visuality · Looking · Seeing

John Berger writes: 'It is a platitude in the teaching of drawing that the heart of the matter lies in the specific process of looking. A line, an area of tone, is not really important because it records what you have seen, but because of what it will lead you on to see'. ${ }^{1}$ Lead you on to see, or lead you on to know? Certainly the process of drawing is connected to looking, depending as it does upon a spectrum of correspondences between eye,

\footnotetext{
T. Norwood $(\square)$

University of Oxford, Oxford, United Kingdom

e-mail: email@tamarinnorwood.co.uk

(C) The Author(s) 2016

F. Callard et al. (eds.), The Restless Compendium, DOI 10.1007/978-3-319-45264-7_13
} 
object, stylus and support. But these correspondences are also home to a kind of blindness, and in my experience of drawing, the specific process of looking and not seeing is what leads you on to know. The form of knowing that emerges is restlessly attentive to the shifting terrain upon which it draws: a terrain explored not by sight but by the interplay of sightlessness, movement and touch.

I set out to draw the woodland around me and the trees come apart before my eyes. The sparse canopy overhead becomes a meshwork geometry of line, texture and gap. A horizontal array of oblongs cuts across the nearest trunks where sunlight hits. It draws a line across the scene, connecting the elbow of a distant trunk, a prominent crop of foliage in the foreground, a thickening of branches towards the right edge of the copse and what might be a figure at work in the distance, near the low horizon. The illuminated trunks become margins that edge patches of deep irregular shade, which in turn present their own geometries: this one almost triangular, this one almost rectangular, this one almost the inverse of that one and so on. The more I look to draw, the less I am able to see the thing I had once seen - a glimpse of springtime woodland in the late afternoon sun - as it becomes subtly different: an observed version of itself, an object, an objectified thing. . $^{\text {. }}$

Such is my experience every time drawing begins. The looking and plotting that happens just before I set pencil to paper, and which continues as drawing goes on, is a kind of restless seeing allied to not seeing and to blindness. I want to examine the dynamics of this restlessness by comparing three distinct images from art history, film theory and anthropology, which together locate the practice of drawing at the intersection of perception and locomotion.

Drawing has been associated with not seeing since its mythical origin in the ancient Greek story of Butades, the potter's daughter who sets out to draw her lover to capture his likeness before he leaves, turning away from him to trace his shadow on to the wall. But her action precipitates his departure, her physical turning away embodying a conceptual turning away that takes place through the act of drawing. By regarding him from a vantage point from which she can capture his likeness, she initiates his withdrawal into objecthood: a withdrawal that draws forth a trace or shadow left behind as a signal of his absence. What she finally draws is not him but his shadow, not the reality of the man but the idea of him,

${ }^{i}$ Cf. Chap. 4. 
projected on to the clay like the shapes that dance inside Plato's cave. It is 'as if seeing were forbidden in order to draw', as Jacques Derrida writes in his treatise on blind drawing, 'as if one drew only on the condition of not seeing'. ${ }^{2}$

So, the act of drawing begins by throwing everything into the dark, and the stylus moves forward into this darkness, on to the page, its movement breaking a path where before there was nothing. Derrida imagines what the stylus might see, pressed so close to the page, and finds it deeply myopic. From the 'aperspective of the graphic act', the stylus is blind both to the form that precedes it (the thing it sets out to draw) and the form that follows it (the drawing that will appear on the page), and instead sees nothing but the immediate present of its 'originary, pathbreaking moment'. ${ }^{3}$ As he constructs an analogy between drawing and blindness, it is striking that he writes less about the absence of sight than the presence of movement and touch. It is not simply that drawing is blind, but that the stylus is a 'staff of the blind' that 'feels its way', providing a tactile proxy for sight; and that the fingertips grope about the page 'as if a lidless eye had opened at the tip of the fingers, as if one eye too many had grown right next to the nail, a single eye, the eye of a Cyclops or one-eyed man'; this lidless eye being, moreover, 'a miner's lamp' whose light makes inscription possible. ${ }^{4}$ Throughout his account of blindness, the conflation of movement, touch and sight is never out of reach. As I draw the woodland, my eyes move fractiously about the fragmented scene before me while my pencil moves likewise about the page, so that touch becomes a close proxy for sight. Movement and touch turn out to be integral to the forms of seeing, not seeing, knowing and not knowing that drawing brings forth. This dynamic is exposed in a second image, this one from film theory, which presents seeing without seeing, or seeing by touch, as a strategy for coming to know.

Haptic visuality is a way of looking in which the eyes behave like fingertips, brushing or caressing the surface of the thing seen; ${ }^{\text {ii }}$ a mode of visuality that has much in common with Derrida's complex of blindness, near-darkness, closeness, and his conflation of sight and touch. Film theorist Laura Marks explores examples of film and video that court this way of being watched. In Seeing is Believing (1991), a video by Shauna Beharry, ${ }^{5}$ a photograph of a piece of fabric is filmed at very close quarters. The closeness means the shot is often out of focus, and

\footnotetext{
ii See Chap. 16.
} 
is very dark when the lens makes contact with the photograph. When the image is dark, it becomes grainy and doubly hard to see. Watching the video, explains Marks, one is primarily aware of surfaces: of the lens, the photograph and the fabric, and of the screen upon which the video plays (indeed, Marks's book is titled The Skin of the Film). Reflecting upon her own experience of watching the video, she writes: 'I realize ... I have been brushing the (image of the) fabric with the skin of my eyes, rather than looking at it'. ${ }^{6}$ In Marks's account, the aperspective of the haptic look is coaxed forth in films and videos that obscure or obstruct vision in one way or another, often through graininess, darkness and lack of focus. These interventions make the viewer vividly aware that whatever is being watched is being watched and caught on film, and moreover that the act of watching and capturing on film is precisely what obscures the thing from sight. The near conflation of these surfaces, each pressed so close to the next, means there is never enough distance to see the whole of any object or indeed to make out surface detail, to understand its topology, or to apprehend the trail the camera lays along its surface. Unlike Butades' gaze, which for Derrida seeks to capture the thing it sees and succeeds in pushing it away, the haptic look brings with it a way of knowing that, by moving with and along the thing it regards, inspires 'an acute awareness that the thing seen evades vision'. ${ }^{7}$ This closeness of touch recalls the probing of the stylus as it makes its way along the surface of the page drawing its object into being, and it suggests a way of coming to know that depends not only upon contact but upon movement. What form of knowing is made possible by the movement of the stylus in drawing?

A third image, that of a wayfarer laying a trail along the surface of a terrain, elaborates this possibility. Anthropologist Tim Ingold provides an account of the dynamics of wayfaring that has much in common with the movement of the haptic lens, and with the 'cautious and bold' creeping forward of the blind men who people Derrida's essay and who 'must advance' bodily through space in order to discover what lies ahead. ${ }^{8}$ For the wayfarer, as for the stylus, lens or figure who gropes in the dark, movement proceeds by means of continuous contact with the terrain, the intimacy of this contact supplying the perceptual clues necessary for advances to be made:

Proceeding on our way things fall into and out of sight, as new vistas open up and others are closed off. ... Thus the knowledge we have of our surroundings is forged in the very course of our moving along them. ${ }^{9}$ 
What Ingold would call the bond between locomotion and perception yields in drawing 'a form of knowledge that is activated or emerges simultaneous to the situation ..., a way of knowing the world that cannot be transferred or banked, nor accumulated into the knowledge of the encyclopedia'. ${ }^{10}$ This description, by the artist Emma Cocker, derives from drawing experiments which emphasize in particular the restlessness of the drawing act. Cocker elicits from the act of drawing a form of knowledge that is vigilant to the changing conditions of the terrain it explores, 'feeling its way [and seizing] opportunities made momentarily visible'. ${ }^{11}$ The form of knowing that emerges in time with the movement of the pencil is forged in the course of this movement and - like a wayfarer foraging for nourishment in the environment around - it is even sustained by it. Drawing depends upon constant, moment-by-moment attentiveness to the changing contingencies of the drawn form as it arrives on the surface of the page; each change in tone, density, direction, velocity feeding the next.iii From the aperspective of the graphic act, to know what lies ahead one must physically move ahead, laying a trail that creates and is created by the richness, complexity and unpredictability of the surface. This is a kind of tactical knowledge 'capable of responding to situations which are contingent, shifting or unpredictable', pushing forward into the unknown and 'producing what is unknown' by these means. ${ }^{12}$

Through these three images (the stylus, the camera lens and the wayfarer), remaining restlessly attentive and vigilant to the blindness inherent in drawing emerges as a strategy for knowing with the thing being drawn, rather than seeking to know it or know about it. Here I intend the word 'with' both in the sense of a mutual engagement, and in the sense of employing the thing being drawn as a strategic means for advancing into new knowledge - working with it as one works with a tool. As the pencil moves about the page attentive to the object it draws into being, what appears is not a drawing of the woodland but a drawing with the woodland: a drawing that employs the woodland to create something entirely new that could not have been created without it. The specific process of looking and not seeing is one of close, tactile engagement quite unlike Butades' experience of turning away and tracing a shadow. A proxy for my unseeing eye, the pencil moves about the paper as though it moved about the surfaces of the trees themselves, laying down marks like caresses that acknowledge their touch as the

\footnotetext{
iii See. Chap. 11 .
} 
very thing that makes the woodland inaccessible to sight. Finally, what I come to know about the woodland by drawing it is that I do not know it. The marks left on the surface of the page are an expression of, and consolation for, the loss of the thing I have drawn away by setting out to capture it on paper.

\section{Notes}

1. John Berger, 'Life Drawing', in Berger on Drawing, ed. Jim Savage (London: Occasional Press, 2007), 3.

2. Jacques Derrida, Mémoires d'avengle: l'autoportrait et autres ruines (Paris: Éditions de la Réunion des Musées Nationaux, 1990), 49.

3. Ibid., 45 .

4. Ibid., $51,4,4$.

5. Shauna Beharry et al., Seeing Is Believing (Montréal, Québec: Groupe Intervention Vidéo, 1991).

6. Laura U. Marks, The Skin of the Film: Intercultural Cinema, Embodiment, and the Senses (Durham, N.C.: Duke University Press, 2000), 127.

7. Ibid., 191.

8. Derrida, Mémoires davengle: l'autoportrait et autres ruines, 5 .

9. Tim Ingold, Lines: A Brief History (London and New York: Routledge, 2007), 87-88.

10. Emma Cocker, 'The Restless Line, Drawing', in Hyperdrawing: Beyond the Lines of Contemporary Art, ed. Phil Sawdon and Russell Marshall (London: I. B. Tauris, 2011), xiv.

11. Ibid.

12. Ibid., xvii.

\section{FURTHER READING}

Detienne, Marcel, and Vernant, Jean-Pierre. Cunning Intelligence in Greek Culture and Society. Chicago, Ill.: University of Chicago Press, 1991.

Hull, John M. Touching the Rock: An Experience of Blindness. 1990. New edition, London: SPCK, 2013.

Nancy, Jean-Luc. Le plaisir au dessin. Paris: Editions Galilée, 2009. [The Pleasure in Drawing, translated by Philip Armstrong. New York, N.Y.: Fordham University Press, 2013].

Schwenger, Peter. 'Words and the Murder of the Thing'. Critical Inquiry 28, no. l (2001): 99-113. 
Tamarin Norwood is an artist and writer working with text, video and sculptural installation. She has recently completed commissions for Tate Britain, Art on the Underground and Modern Art Oxford, and through 2016 is artist-writer in residence at Spike Island (Bristol).

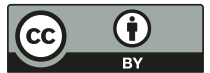

This chapter is distributed under the terms of the Creative Commons Attribution 4.0 International License (http://creativecommons.org/ licenses/by/4.0/), which permits use, duplication, adaptation, distribution and reproduction in any medium or format, as long as you give appropriate credit to the original author(s) and the source, a link is provided to the Creative Commons license and any changes made are indicated.

The images or other third party material in this chapter are included in the work's Creative Commons license, unless indicated otherwise in the credit line; if such material is not included in the work's Creative Commons license and the respective action is not permitted by statutory regulation, users will need to obtain permission from the license holder to duplicate, adapt or reproduce the material. 